\title{
Resistência aos Antibacterianos
}

\section{Resistance to Antibacterials}

Rita Oliveira ${ }^{1}$, Teresa Aires ${ }^{1}$

\section{RESUMO}

Resistência aos antibacterianos é a capacidade que as bactérias adquirem de sobreviverem a concentrações de fármacos que as inibem ou matam e está associada à excessiva e inadequada utilização dos antibacterianos.

Existem hoje bactérias extraordinariamente resistentes a múltiplos tipos de antibacterianos: as "superbactérias".

Se nada for feito, em 2050 poderão morrer 10 milhões de pessoas em todo o mundo, vítimas de infeções por bactérias resistentes.

PALAVRAS-CHAVE: Antibacterianos; Farmacorresistência Bacteriana Múltipla; Resistência Microbiana a Medicamentos

\section{ABSTRACT}

Antibacterial resistance is the acquire ability of bacteria to survive drug concentrations that inhibit or kill and is associated with excessive and inappropriate use of antibacterials.

There are now bacteria unusually resistant to multiple types of antibacterials: the "superbugs".

If nothing will be done, by 2050 will die 10 million people worldwide, victims of infections by resistant bacteria.

KEYWORDS: Anti-Bacterial Agents; Drug Resistance, Microbial; Drug Resistance, Multiple, Bacterial

1. Serviço de Farmácia - CUF Infante Santo Hospital, Lisboa, Portugal; Farmácias Cluster Tejo - CUF Cascais Hospital, Cascais, Portugal. Serviços Farmacêuticos - José de Mello Saúde, Carnaxide, Portugal.

Recebido: 03/06/2016 - Aceite: 14/06/2016 


\section{INTRODUÇÃO}

A descoberta dos antibacterianos revolucionou a prática da medicina e salvaram já milhões de vidas!

No entanto, paira sobre esta valiosíssima arma terapêutica, uma ameaça crescente, a resistência aos antibacterianos, que tem como resultado a deterioração da sua eficácia.

A resistência aos antibacterianos é definida como a capacidade que as bactérias adquirem de sobreviverem a concentrações de fármacos que inibem ou matam determinados microrganismos e outros da mesma espécie e está associada à excessiva e inadequada utilização dos antibacterianos. ${ }^{1}$

A resistência aos antibacterianos constitui um dos maiores desafios que vamos ter de enfrentar, uma vez que se prevê que até 2050 poderão morrer, vítimas de infeções por microrganismos resistentes, 10 milhões de pessoas em todo o mundo. ${ }^{2,3}$

Por causa da resistência aos antibacterianos, muitas infeções bacterianas tornaram-se impossíveis de tratar. $O$ termo "superbactérias" refere-se a microrganismos com morbilidade e mortalidade aumentada, dotado de elevados níveis de resistência às classes de antibacterianos especificamente recomendadas para o seu tratamento. ${ }^{4}$

As opções terapêuticas são reduzidas e os períodos de cuidados hospitalares são prolongados e mais dispendiosos. Estas bactérias, além de constituírem um problema para os clínicos que com elas têm de lidar, são também responsáveis por elevados encargos financeiros para os sistemas de saúde que cientes do problema já se encontram a coordenar esforços de forma a tornar possível gerir a crise instalada. ${ }^{5}$

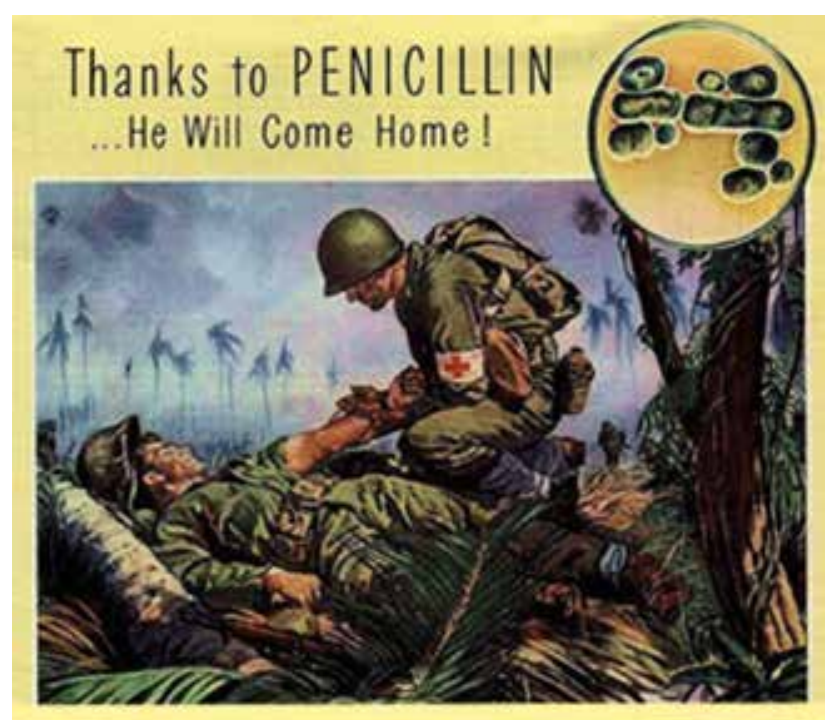

FIGURA 1. Penicilina na guerra. Adaptado de The National WWII Museum.

\section{PERSPETIVA HISTÓRICA}

A gestão de infeções bacterianas remonta ao antigo Egipto, Grécia e China, no entanto, a mudança de paradigma ocorreu verdadeiramente com a descoberta da Penicilina por Sir Alexander Fleming em 1928.

Os antibacterianos foram prescritos pela primeira vez no tratamento de infeções graves por volta de 1940. Nessa época, a penicilina curou milhares de doentes, tendo sido muito bem-sucedida no controlo de infeções bacterianas na Segunda Guerra Mundial, até surgirem as primeiras resistências na década de cinquenta.

Para dar resposta a esta situação, foram descobertos, desenvolvidos e comercializados, novos antibacterianos beta-lactâmicos que permitiram restaurar a confiança. ${ }^{1,3}$

No entanto, surgem no Reino Unido em 1962 e nos Estados Unidos em 1968, os primeiros casos documentados de Staphylococcus aureus resistentes à meticilina (MRSA).

O desenvolvimento de resistências tornou-se uma constante à medida que se foram desenvolvendo novas moléculas. ${ }^{6,7}$

Em 1972, surgiu a vancomicina, introduzida na prática clínica para o tratamento da resistência à meticilina em Staphylococcus aureus e Staphylococcus coagulase-negativa. Com o aparecimento desta nova molécula, considerava-se na altura ser quase impossível a ocorrência de estirpes resistentes aos antibacterianos existentes, mas mais uma vez, pouquíssimos anos depois, em 1979 e 1983, foram registados os primeiros casos de resistência à vancomicina em Staphylococcus coagulase-negativa.

Durante o período que decorreu entre os finais dos anos 60 até ao início dos anos 80, a indústria farmacêutica respondeu sempre de forma dinâmica à problemática da perda de eficácia dos antibacterianos, desenvolvendo novas moléculas cada vez mais agressivas. Até que, constrangimentos legais associados à investigação na área dos antibacterianos, grave crise financeira, surgimento de novas doenças e de novas áreas de investigação clínica com maior retorno financeiro, fizeram com que os antibacterianos deixassem de ser interessantes para a indústria farmacêutica.

Acresce que o custo unitário dos antibacterianos tem vindo a baixar ao longo do tempo e tornou-se muito baixo em comparação com outros medicamentos, nomeadamente os utilizados para o tratamento do cancro e outras patologias infeciosas crónicas, tornando esta classe farmacológica menos "atrativa" para a investigação e investimento por parte da indústria farmacêutica.

Por outro lado, a disponibilidade, a facilidade de utilização e o baixo custo, levou a uma perceção de "baixo 
valor" da parte da população em geral que não é fácil combater. ${ }^{2,4,5}$

Como resultado, em 2016, muitas décadas depois dos primeiros doentes terem sido tratados com antibacterianos, estamos novamente na presença de infeções bacterianas sem tratamento. ${ }^{8}$

\section{MECANISMOS DE RESISTÊNCIA}

A resistência aos antibacterianos foi pela primeira vez referida por Sir Alexander Fleming 17 anos após ter descoberto a penicilina que alertou desde logo para o perigo do seu uso abusivo "public will demand [the drug and] ... then will begin an era ... of abuses."

A resistência é um fenómeno ecológico que ocorre como resposta da bactéria à exposição constante aos antibacterianos. Na presença de um antibacteriano, uma mutação que faça com que a bactéria seja resistente a esta substância tóxica é uma enorme vantagem.

Os genes da resistência evoluíram através da acumulação de mutações que permitem a sobrevivência na presença de moléculas tóxicas. Erros ou mutações na replicação do ácido desoxirribonucleico (ADN) aquando da divisão celular e multiplicação bacteriana afetam negativamente o microrganismo, mas por vezes a mutação tem efeito positivo sobre a sua sobrevivência., ${ }^{1,4}$

Com isto em mente, não é surpreendente que para a maioria dos nossos antibacterianos, que vêm de fontes naturais (como as bactérias do solo), já exista um gene que possa ser responsável por mecanismos de resistência. Como as bactérias crescem, multiplicam-se rapidamente, sofrem mutações e podem trocar material genético entre linhagens da mesma espécie ou de espécies diferentes, torna-se bastante célere o aparecimento de uma população descendente resistente.

São vários os mecanismos que as bactérias podem utilizar e os mesmos variam de acordo com a espécie e o meio ambiente onde estão inseridas. ${ }^{8}$

As bactérias podem produzir sistemas de transporte, bombas de efluxo, que removem ativamente substâncias nocivas da célula. Estas bombas são uma estratégia de resistência, contudo, não são específicas para os antibacterianos, são utilizadas para um elevado número de outras substâncias tóxicas.

Outro dos mecanismos de resistência consiste na eliminação do efeito antibacteriano através de uma proteína capaz de destruir uma parte essencial da molécula do fármaco, tornando-o ineficaz. As bactérias adquirem a capacidade de encontrar formas alternativas para exe- cutar determinadas tarefas celulares que dependiam da proteína inibida pelo antibacteriano. Alcançam este tipo de resistência, produzindo proteínas redundantes, ou seja back-ups, que cumprem as mesmas funções da proteína inibida. Esta estratégia de bypass verifica-se por exemplo no caso do MRSA, uma das "superbactérias".

As próprias bactérias podem também produzir moléculas antibacterianas, porque esta capacidade permite- Ihes sobreviver aniquilando outras bactérias ou fungos que competem pelos mesmos recursos naturais.

Como é que os seres humanos contribuíram para a epidemia que estamos a enfrentar? O principal responsável é o uso excessivo e/ou inapropriado dos antibacterianos. A prescrição antibiótica incorreta tem benefício terapêutico muito questionável e expõe os doentes a potenciais complicações, tal como toxicidade renal, toxicidade hepática, entre outras. Concentrações séricas sub-terapêuticas ou inferiores à concentração inibitória mínima (MIC) resultam no desenvolvimento de resistência aos antibacterianos. $^{9-11}$

Quando os doentes suspendem tratamento com antibacterianos porque apresentam sinais de melhoria da infeção, tomando uma dose incompleta, aumenta a probabilidade de recidiva da infeção que agora será resistente ao antibacteriano previamente administrado. Os antibacterianos são também empregues excessivamente na pecuária para tratar animais doentes, contudo, é conhecida a sua utilização com o intuito de aumentar o tamanho (e o valor) do gado, dando aos agricultores ainda mais incentivos para o excesso de utilização. São também utilizados na agricultura, na pulverização de árvores de fruto com pesticidas à base de tetraciclinas e estreptomicina. Em ambas as situações é afetado o ambiente microbiano, uma vez que os antibacterianos ao serem ingeridos pelos animais são excretados na urina e fezes, que ao serem transformados em fertilizantes, acabam por ser dispersos, indo contaminar as águas subterrâneas e de superfície.

A comercialização de produtos de higiene com antibacterianos também pode contribuir para agravar este problema, pela inibição do sistema imunitário tornando as crianças e adultos mais vulneráveis às bactérias presentes no ambiente. A vulnerabilidade do sistema imunitário pode levar a um aumento da morbilidade e mortalidade devido a agentes que em condições normais não seriam virulentos.

Habitualmente, as infeções resistentes são detetadas através de tentativa e erro: tratamentos consecutivos ineficazes. Todos os métodos eficientes de determinação da sensibilidade bacteriana podem melhorar muito o tra- 
tamento de infeções e ajudar a conter possíveis surtos de resistência. 6,7 Enquanto a procura de novos tratamentos para infeções resistentes a antibacterianos permanece nas "agendas" das empresas farmacêuticas e das entidades nacionais e internacionais de saúde, torna-se imperativo ajustar o comportamento e as atitudes humanas em relação à utilização dos antibacterianos. ${ }^{8}$

Atualmente a "superbactéria" mais conhecida é o Staphylococcus aureus resistente à meticilina (MRSA), que embora não tenha a mesma reputação histórica do Mycobacterium tuberculosis, é sem dúvida a mais mediatizada. Nos últimos anos este agente patogénico multirresistente emergiu como a principal causa de infeção hospitalar e, recentemente, o MRSA foi transferido para a comunidade, apresentando características de transmissão e virulência aumentada. Um outro habitante dos hospitais conhecido há muito tempo, é a bactéria anaeróbia Clostridium difficile cada vez mais associada a infeções intestinais graves, devido ao uso excessivo de antibacterianos como as cefalosporinas, penicilinas mais recentes e fluoroquinolonas. ${ }^{12}$

\section{ANTIBACTERIANOS RECENTEMENTE APROVADOS}

Os antibacterianos naturais geralmente apresentam estruturas químicas complexas importantes para as interações específicas e reconhecimento dos alvos macromoleculares em bactérias patogénicas. Neste contexto, nos últimos 10 anos os investigadores têm pesquisado fontes naturais ainda pouco exploradas, pois organismos obtidos em novos ecossistemas estão frequentemente associados a nova diversidade química. Tem sido explorada uma ampla diversidade de organismos nos mais diversos habitats, especialmente em locais de condições ambientais extremas: ambientes que possuem alterações drásticas de temperatura, pH, humidade e/ou luminosidade. $O$ crescente interesse por bactérias marinhas, especialmente actinobactérias, tem levado à descoberta de substâncias com atividade antitumoral e antibacteriana. ${ }^{13,14}$

Embora a investigação de novas moléculas antibacterianas não seja a prioridade da indústria farmacêutica, o interesse em dar resposta à emergência das "super-

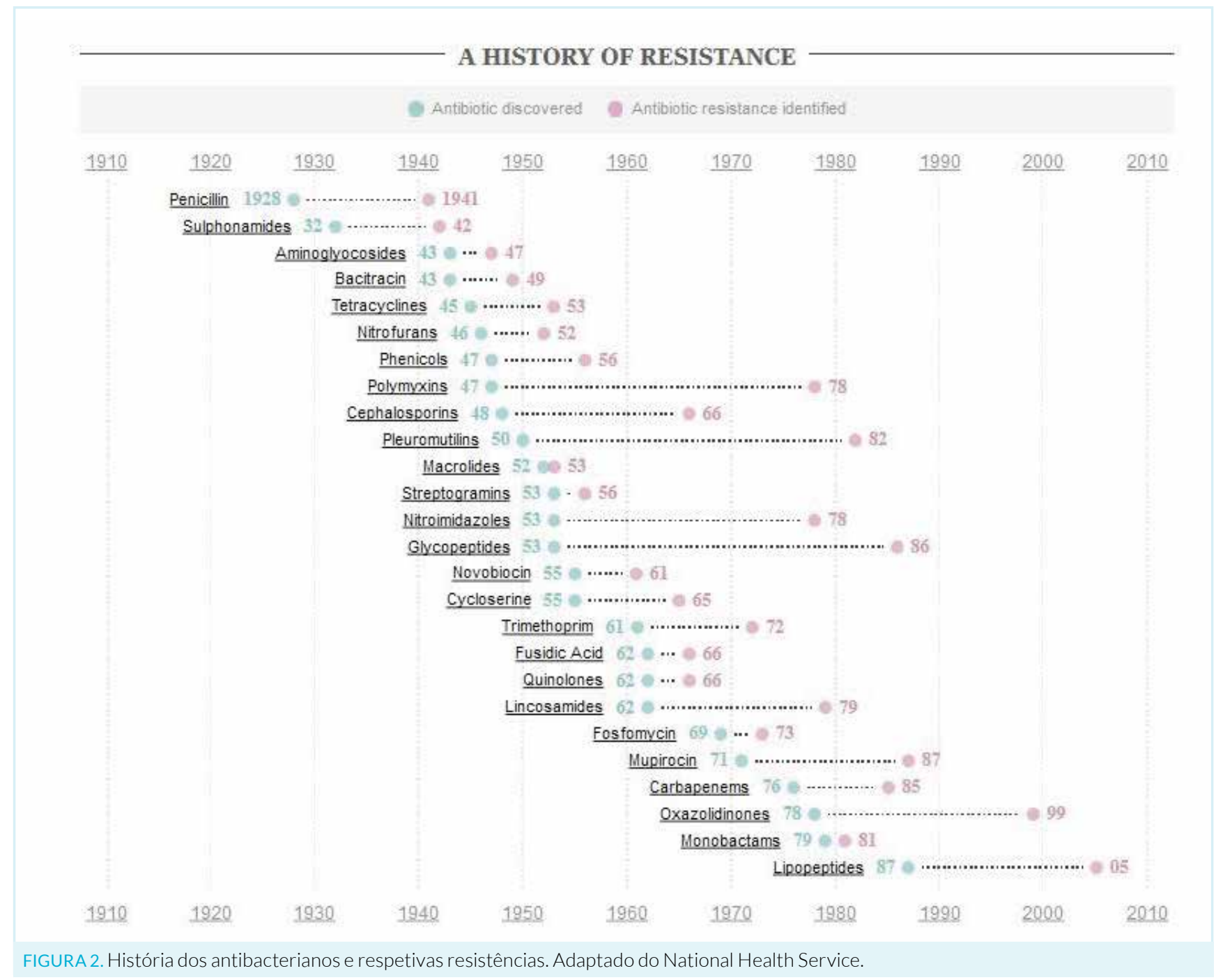


bactérias" fica corroborado com os exemplos que se seguem. ${ }^{15,16}$

Doripenem, aprovado pela FDA em 2007, é um carbapenem usado para tratar infeções graves causadas por bactérias gram-negativas, contudo, a disseminação de bactérias resistentes aos carbapenems (Enterobacteriaceae spp) reduziu a eficácia global deste antibacteriano. $\bigcirc$ doripenem foi aprovado para o tratamento de pneumonia nosocomial, incluindo pneumonia associada ao ventilador.

Telavancina é um glicopéptido que recebeu a aprovação da FDA em 2008 para o tratamento de infeções na pele e tecidos moles provocados por bactérias gram-positivas. $O$ uso de telavancina é limitado porque apenas pode ser administrado por via intravenosa e não permite continuidade no ambulatório.

Ceftarolina, é uma cefalosporina de quinta geração que foi aprovada em 2015 e ao contrário das outras cefalosporinas, é ativa contra MRSA. Estudos in vitro têm mostrado que a ceftarolina tem propriedades bactericidas e capacidade de inibir a síntese da parede celular das bactérias MRSA e Streptococcus pneumoniae não suscetível à penicilina devido à sua afinidade para as proteínas de ligação à penicilina (PLPS) alteradas encontradas nestes organismos. A ceftarolina não é ativa contra estirpes de Enterobacteriaceae spp produtoras de ß-lactamases, carbapenemases, metalo ß-lactamases ou cefalosporinases.

Tedizolida, é um novo antibacteriano da classe das oxazolidinonas, aprovado pela FDA em 2014, que oferece vantagens quando comparado com o linezolida.

Trata-se de um pró-fármaco que é convertido in vivo por ação das fosfatases séricas. Devido à sua estrutura química, este antibacteriano demonstrou ter maior atividade antibacteriana in vitro do que a linezolida. Não existe uma correlação direta entre esta aparente maior atividade e uma maior eficácia clínica, contudo, a dose diária é de 200 miligramas numa toma única durante 6 dias versus 10 dias no caso do linezolida. As MICs da tedizolida são inferiores à linezolida para Staphylococcus spp, Streptococcus spp e Enterococcus spp. Sensivelmente 80\% das estirpes resistentes à linezolida foram inibidas por tedizolida a uma concentração menor ou igual a 4 microgramas por mililitro.

Dalbavancina, trata-se de um glicopéptido de administração injetável que é ativo contra bactérias gram-positivas e que foi aprovado pela FDA em 2014. As MICs da dalbavancina para espécies de Staphylococcus spp são significativamente mais baixas quando comparadas com as da vancomicina. Estudos clínicos randomizados de fase 3 demonstraram a não inferioridade da dalbavancina quan- do comparada com a vancomicina e com a linezolida no tratamento de infeções da pele e de tecidos moles.

Oritavancina, é um glicopéptido que foi aprovado em 2014 e demonstrou ser ativo contra bactérias gram-positivas incluindo MRSA, VRE e Staphylococcus aureus resistentes à vancomicina (VRSA). Oritavancina é administrada por via intravenosa, não é metabolizada e é excretada de forma inalterada. Não carece de ajuste posológico em situações de disfunção renal e/ou hepática leve a moderada, idade, sexo ou raça. Foi demonstrado que a oritavancina não é inferior à vancomicina para o tratamento de infeções cutâneas.

Ceftolozano/tazobactam, esta nova combinação de uma cefalosporina (ceftolozano) e um inibidor de ß-lactamases (tazobactam) que recebeu a aprovação da FDA em 2014. É principalmente ativo contra infeções causadas por bactérias gram-negativas, nomeadamente infeções intra-abdominais graves, infeções do trato urinário e pielonefrite aguda. Demonstra excelente atividade in vitro contra Escherichia coli, Citrobacter koseri, Morganella morganii, Proteus mirabilis, Serratia marcescens, Salmonella spp e Klebsiella pneumoniae. Também apresenta boa atividade contra Pseudomonas aeruginosa, sendo atualmente a cefalosporina com maior atividade contra esta bactéria pois é estável na presença de determinadas ß-lactamases e não é afetada pela perda de porinas da membrana externa da bactéria (diminuição da permeabilidade da membrana externa das bactérias através de mutações e modificações nas proteínas que permitem a entrada de nutrientes e outros elementos para o interior da célula) ou pela presença de bombas de efluxo ativas.

Num estudo multicêntrico, randomizado e duplamente cego, este antibacteriano associado ao metronidazol demonstrou não inferioridade quando comparado com o meropenem no tratamento de infeções intra-abdominais.

Noutro estudo também multicêntrico, randomizado e duplamente cego, demonstrou-se que as taxas de cura clínica para o ceftolozano/tazobactam são comparáveis às da levofloxacina no tratamento de infeções complicadas do trato urinário, incluindo pielonefrite.

Ceftazidima/avibactam, trata-se de outra combinação de uma cefalosporina (ceftazidima) e um inibidor de ß-lactamases (avibactam) que foi aprovado pela FDA em fevereiro de 2015. É ativa contra bactérias gram-negativas, tais como Pseudomonas aeruginosa e muitas espécies de Enterobacteriaceae. A informação disponível é limitada em relação à atividade desta combinação sobre as várias espécies de Acinetobacter ou em relação à maioria das bactérias anaeróbias (exceções: Bacteroides fragilis, Clostridium perfringens, Prevotella spp, Porphyro- 
monas spp). O papel futuro da ceftazidima/avibactam inclui o tratamento de infeções causadas por bactérias gram-negativas produtoras de ß-lactamases, Klebsiella pneumoniae produtoras de carbapenemases. Poderá ser utilizada em combinação com o metronidazol em casos de infeções polibacterianas. ${ }^{13-16}$

\section{ANTIBACTERIANOS EM INVESTIGAÇÃO E DESENVOLVIMENTO}

Dentro dos antibacterianos que estão em pipeline incluem-se aminoglicosídeos de nova geração, inibidores de ß-lactamases, quinolonas, quetólidos (semelhantes aos macrólidos), tetraciclinas e oxazolidinonas.

Em dezembro de 2014, cerca de 37 novos antibacterianos para o tratamento de infeções bacterianas graves estavam em investigação e desenvolvimento clínico.

Contudo, a taxa de sucesso é baixa (um em cada cinco) e mesmo que se venha a demonstrar em ensaios clínicos que estes agentes são seguros e eficazes, é provável que os mesmos só estejam disponíveis para utilização clínica daqui a três a cinco anos.

Atualmente existem vários antibacterianos em fase III de ensaios clínicos: RPX709 associado ao meropenem (inibidor de ß-lactamases + carbapeneme); delafloxacina (fluoroquinolona); eravaciclina (tetraciclina); plazomicina (aminoglicosídeo) e solitromicina (macrólido). ${ }^{14,17}$

RPX709 associado ao meropenem visa dar resposta ao problema da presença de carbapenemases em Enterobacteriaceae no hospitalar que ameaçam a eficácia dos antibacterianos carbapenems e dos ß-lactâmicos. Estas infeções estão associadas a elevadas taxas de mortalidade e as opções de tratamento são limitadas. A perda da eficácia dos Carbapenems face a A. baumannii, P. aeruginosa e às bactérias da família Enterobacteriaceae força os médicos a recorrer a opções tais como: aminoglicosídeos, polimixina B, colistina, tigeciclina ou a várias combinações destes.

O RPX7009 é o novo inibidor das ß-lactamases e carbapenamases para a potenciação dos carbapenems face a infeções por bactérias da família Enterobacteriaceae. Está a ser investigado para o tratamento de infeções de gram-negativas graves, tais como infeções do trato urinário complicadas, pielonefrites agudas, pneumonias adquiridas em meio hospitalar e/ou associadas ao ventilador e até mesmo em bacteremias, sendo que os resultados dos ensaios clínicos estão previstos para 2016.

Delafloxacina é uma nova fluoroquinolona para o tratamento de infeções agudas da pele e tecidos moles cau- sados por bactérias gram-positivas (MRSA) e gram-negativas.

A eravaciclina é uma tetraciclina com atividade antibacteriana contra um largo espectro de bactérias sensíveis e multirresistentes incluindo gram-positivas, gram-negativas, anaeróbios e bactérias atípicas. Parece ser eficaz contra Acinetobacter baumannii e bactérias da família Enterobacteriaceae, Klebsiella pneumoniae resistentes aos carbapenems.

A plazomicina está a ser avaliada para o tratamento da pneumonia adquirida no hospitalar causada por bactérias Enterobacteriaceae resistentes aos carbapenems (CRE), pneumonia associada ao ventilador, infeções intra-abdominais complicadas e bacteremia relacionada com o uso do cateter.

Solitromicina é um macrólido de $4^{a}$ geração e o primeiro fluoroketolide, eficaz contra a maioria das bactérias resistentes aos macrólidos. Apresenta eficácia contra S. pneumoniae resistente e contra Legionella, Chlamydophila, Chlamydia, Mycoplasma, Mycobacterium avium, Enterococcus e MRSA. É muitíssimo mais potente do que a azitromicina e é ativo contra estirpes resistentes a este antibacteriano. ${ }^{13,17}$

\section{NOVAS ABORDAGENS NO TRATAMENTO DE INFEÇÕES BACTERIANAS}

A terapia fágica recorre aos bacteriófagos, também denominados de fagos - vírus que infetam exclusivamente células bacterianas através do reconhecimento de proteínas da parede celular das bactérias e consequente ligação a recetores específicos. Os fagos são específicos para cada tipo de célula e podem reproduzir-se e destruir a célula hospedeira, sendo este denominado fago lítico, ou reproduz-se mais tarde, integrando o ácido nucleico do genoma da bactéria hospedeira, sendo denominado de fago lisogénico. ${ }^{13}$

Uma das limitações é a especificidade do fago e a necessidade de preparação de um bacteriófago específico para cada estirpe bacteriana, contudo, já é possível contornar esse problema. A probabilidade de ocorrerem casos de imunogenicidade devido ao desenvolvimento de anticorpos anti-fagos pelo sistema imunitário também constitui uma limitação.

Os fagos foram descobertos no início do século XX e com o problema do aumento das bactérias multirresistentes os bacteriófagos estão a ser estudados como uma opção terapêutica possível para fazer frente à resistência antibacteriana. ${ }^{18-21}$ 
Outra linha de investigação são os péptidos catiónicos

alfa-hélice que são análogos sintéticos do DNA ou do RNA e têm a capacidade de inibir a expressão de genes específicos. O seu mecanismo de ação consiste na destabilização da membrana celular bacteriana, de forma a alterar a permeabilidade, comprometendo a integridade e sobrevivência da bactéria. ${ }^{13}$

Esta nova abordagem pode ser extremamente útil contra as infeções por P. aeruginosa, S. pneumoniae e S. aureaus. ${ }^{18-21}$

\section{GESTÃO DA CRISE "RESISTÊNCIA AOS ANTIBACTERIANOS"}

$\bigcirc$ Centers for Disease Control and Prevention (CDC), assim como outras organizações e especialistas têm emanado recomendações dirigidas aos profissionais de saúde bem como definido requisitos a que devem obedecer as instalações hospitalares de forma a reduzir a resistência aos antibacterianos. ${ }^{22,23}$

Entre as recomendações, destaca-se por exemplo, a necessidade de serem implementadas políticas de utilização de antibacterianos; criação de protocolos de profilaxia e de terapêutica com doses e dias de terapêuticos definidos; aumentar a rapidez e a precisão no diagnóstico laboratorial com vista a uma prescrição mais dirigida; otimizar os esquemas terapêuticos e definir e implementar uma "Política de Antibacterianos" que deverá integrar os seguintes pontos:

Liderança e compromisso que pressupõem dedicarem recursos humanos, recursos tecnológicos e financeiros.

Responsabilidade que implica a nomeação de líderes responsáveis pelos resultados da implementação da "Política de Antibacterianos". A experiência dita que o sucesso é alcançado com um líder médico infeciologista.

Expertise em medicamentos com a nomeação de líderes farmacêuticos responsáveis pela boa e racional utilização dos antibacterianos.

Ações que passam pela implementação de pelo menos uma ação recomendada, como a avaliação sistemática da adequação do tratamento.

Monitorização que supõe o acompanhamento da prescrição de antibacterianos e dos padrões de resistência.

Elaboração de relatórios como forma de feedback periódico sobre o uso e resistência dos antibacterianos a médicos, enfermeiros, farmacêuticos, gestores e restante equipa.

Por último, formação dirigida a médicos, enfermeiros, farmacêuticos e restantes profissionais sobre a resistência e otimização da prescrição.

É importante também que estas políticas não se cinjam apenas ao ambiente hospitalar, mas que orientem também a prescrição no ambulatório, que por ser menos controlada, constitui muitas vezes a origem do problema.

Estas políticas deverão ainda incluir campanhas de sensibilização das populações no que respeita à utilização racional dos antibacterianos. $8,24,25$

\section{CONCLUSÃO}

Recentemente, os meios de comunicação social têm lançado frequentes alertas para a emergência de bactérias extraordinariamente resistentes a múltiplos tipos de antibacterianos apelidando-as de "superbactérias".

Vários fatores contribuíram para o aumento descontrolado de estirpes resistentes, dos quais se destaca a prescrição e a automedicação de antibacterianos para tratamento de infeções de menor gravidade e de etiologia não bacteriana.

A disseminação de estirpes resistentes e de outras multirresistentes em meio hospitalar deve-se essencialmente à inexistência ou ao incumprimento de procedimentos básicos de controlo de infeção, como a higienização das mãos, mas também e sobretudo à transferência de doentes infetados entre hospitais e entre hospitais e a comunidade. ${ }^{26,27}$

A propagação das bactérias "exclusivas" hospitalares para a comunidade, coloca em risco idosos, doentes imunocomprometidos, cada vez em maior número, crianças, etc.

É essencial implementar programas de vigilância nacionais e internacionais com a criação de metodologias uniformizadas.

Atualmente existem vários programas que visam minimizar a crescente prevalência da resistência aos antibacterianos: European Antimicrobial Resistance Surveillance (EARSS), uma rede europeia de sistemas de vigilância nacionais, onde Portugal se encontra representado pelo Laboratório Nacional de Referência das Resistências aos antibacterianos e o "Plano de Ação Nacional para a Redução do Uso de Antibióticos nos Animais" da Direção Geral de Alimentação e Veterinária.

Portugal ocupa o $3^{\circ}$ lugar dos países da União Europeia com maior taxa de prescrição e consumo de antibacterianos. Cabe aos profissionais de saúde, consciencializar-se dos perigos que a prescrição indevida dos antibacterianos pode causar nos seres humanos e sensibilizar a comunidade da relevância do tema. 
Devemos aprender com os erros do passado, pois só desta forma poderemos perspetivar um futuro mais saudável para toda a comunidade..$^{28}$

CONFLITOS DE INTERESSE: Os autores declaram a inexistência de conflitos de interesse na realização do presente trabalho.

FONTES DE FINANCIAMENTO: Não existem fontes externas de financiamento para a realização deste artigo.

\section{REFERÊNCIAS}

1. Davies J, Davies D. Origins and evolution of antibiotic resistance. Microbiol Mol Biol Rev. 2010;74:417-33.

2. World Health Organization. WHO multi-country survey reveals public misunderstanding about antibiotic resistance. Organização Mundial de Saúde. 2015. [consultado 28 maio 2016]. Disponível em: http://www.who.int.

3. Gross M. Antibiotics in crisis. Curr Biol. 2013; 23:R1063.

4. Kelland K. New "Superbug" Gene Found in Animals and People in China. Sci Am. 2015. [consultado 28 maio 2016]. Disponível em: http://www.scientificamerican.com/article/new-superbug-gene-found-in-animals-and-people-in-china/.

5. Van Boeckel TP, Gandra S, Ashok A. Global antibiotic consumption 2000 to 2010: an analysis of national pharmaceutical sales data. Lancet Infect Dis. 2014;14:742-50.

6. Rossolini GM, Arena F, Pecile P, Pollini S. Update on the antibiotic resistance crisis. Clin Opin Pharmacol. 2014;18:56-60.

7. Piddock $L J$. The crisis of no new antibiotics - what is the way forward? Lancet Infect Dis. 2012;12:249-253.

8. Read AF, Woods RJ. Antibiotic resistance management. Evol Med Public Health. 2014;2014:147.

9. U.S. Food and Drug Administration. Regulation to Help Ensure Judicious Use of Antibiotics in Food-Producing Animals. [consultado 28 maio 2016]. Disponível em: http://www.fda.gov.

10. Michael CA, Dominey-Howes D, Labbate M. The antibiotic resistance crisis: causes, consequences, and management. Front Public Health. 2014;2:145.

11. Monteiro ARP. Resistência Adquirida a Quinolonas em Enterobacteriaceae isoladas de suiniculturas Portuguesas. Porto: Universidade Fernando Pessoa, Faculdade de Ciências; 2011.

12. Winter G. Beta-lactam antibiotics can make MRSA infection worse. The Pharm Journal. 2015. [consultado 28 maio 2016]. Disponível em: http://www.pharmaceutical-journal.com/news-and-analysis/news/beta-lactam-antibiotics-can-make-mrsa-infection-worse/20200058.article.

13. Oliveira D, Momesso L, Tallarico M. Antibióticos: importância terapêutica e perspectiva para a descoberta e desenvolvimento de novos agentes. Quim Nova. 2010;33:667-79.
14. Anderson J, Balasegeram M, Bonney M, Chaudhry S, Davies DS, Farrar J, et al. Securing new drugs for future generations: the pipeline of antibiotics. In: O'Neill J, editor.The review on antimicrobial resistance. Philadel phia: US Centers for Disease Control; 2013.

15. Chamber HF, DeLeo FR. Waves of resistance: Staphyloccocus in the antibiotic era. Nat Rev Microbiol. 2009;7:629-41.

16. Perry J, Waglechner N, Wright G. The Prehistory of Antibiotic Resistance. Cold Spring Harb Perspect Med. 2016;6:1-9.

17. ClinicalTrials.gov. Efficacy and Safety study of oral solithromycin (cem-101) compared to oral moxifloxacin in treatment of patients with community-acquired bacterial pneumonia. ClinicalTrials.gov 2014. [consultado 28 maio 2016]. Disponível em: https://clinicaltrials.gov/ct2/show/NCT01756339.

18. Azevedo A. Desenvolvimento de um sistema terapêutico com bacteriófagos para administração por via inalatória, com recurso a nanoencapsulação como modelo para tratamento de pneumonia bacteriana. Porto: Universidade Fernando Pessoa, Faculdade de Ciências; 2010.

19. Golkar Z, Bagazra O, Pace DG. Bacteriophage therapy: a potential solution for the antibiotic resistance crisis. J Infect Dev Ctries. 2014;8:129-36.

20. Bangert M, Wright AK, Rylance J, Kelly MJ , Wright AD, Carlone GM, et al. Immunoactivating peptide p4 augments alveolar macrophage phagocytosis in two diverse human populations. Antimicrob Agents Chemother. 2013;57:4566-9.

21. Gould IM, Bal AM. New antibiotic agents in the pipeline and how they can overcome microbial resistance. Virulence. 2013;4:185-91.

22. Luyt CE, Brechot N, Trouillet JL, Chastre J. Antibiotic stewardship in the intensive care unit. Crit Care. 2014;18:480.

23. Garcia BS. The antimicrobial therapy of the future: combating resistances. Infect Dis Ther. 2014;2:1-7.

24. Spellberg B, Gilbert DN. The future of antibiotics and resistance: a tribute to a career of leadership by John Bartlett. Clin Infect Dis. 2014; 59 (suppl 2):S71-S75.

25. Smith R, Mikanatha N, Read A. Antibiotic resistance: a primer and call to action. Health Commun. 2015;30:309-314.

26. Bartlett JG, Gilbert DN, Spellberg B. Seven ways to preserve the miracle of antibiotics. Clin Infect Dis. 2013;56:1445-50.

27. Instituto Nacional de Saúde Dr. Ricardo Jorge. Resistência ao Antibacterianos.2010. [consultado 28 maio 2016]. Disponível em: http://www.insa.pt/sites/INSA/Portugues/AreasCientificas/DoencasInfecciosas/AreasTrabalho/ResistencAnti/Paginas/inicial.aspx.

28. Lushniak BD. Antibiotic resistance: a public health crisis. Public Health Rep. 2014;129:314-6. 